\title{
Reconciling chemical weathering rates across scales: insights from U-series isotopes in volcanic weathering clasts from Basse- Terre Island (Guadeloupe)
}

\author{
Lin MA', JiYe GuO', YvetTe PEREYRA', JACQUELINE \\ ENGEL', Jerome GaIllardeT' ${ }^{2}$, PETER SAK \\ DEPARTMENT OF GEOLOGICAL SCIENCES, UnIVERSITY OF \\ TeXas at El PASO, El PASO, TX 79968, USA, \\ LMA@UTEP.EDU \\ ¿UNIVERSITÉ DE PARIS, INSTITUT DE PHYSIQUE DU GLOBE DE \\ PARIS, CNRS, F-75005 PARIS, FRANCE \\ DEPartment of EARTH SCIENCES, Dickinson College, \\ CARLISLE, PA 17013, USA
}

We utilized a U-series isotopic technique to directly determine the chemical weathering rates recorded in volcanic weathering clasts on the tropical volcanic Basse-Terre Island of French Guadeloupe. Our U-series dataset was systematically compiled from 15 individual clasts collected from eight andesitic watersheds along a gradient of precipitation ranging from $\sim 1600 \mathrm{~mm} / \mathrm{yr}$ to $6400 \mathrm{~mm} / \mathrm{yr}$ on this island. Total rind formation ages, the length of time it took for these weathering clasts to form from andesitic rock fragments or volcanic clasts in the soil zones, range from 60 kyr to $300 \mathrm{kyr}$. The rind ages in individual clasts generally increase almost linearly with distance away from the corerind boundary. The derived clast weathering rates range from $0.08 \pm 0.04$ to $0.34 \pm 0.01 \mathrm{~mm} / \mathrm{kyr}$, and the rates exhibit a strong positive correlation $\left(\mathrm{R}_{2}=0.74\right)$ with the annual runoff values of these watersheds. This correlation documents the first direct evidence that weathering over geological timescales on the island is controlled by the amount of precipitation and corroborates the relationship that was previously reported for the riverine weathering fluxes at Basse-Terre Island in Guadeloupe, but measured with much shorter time scales. The clast-scale rates (length scale of $\mathrm{mm}$ ) are compared to the watershed-scale rates of Basse-Terre Island (length scale of $\mathrm{km})$ : constantly higher rates $(\sim 1800 \pm$ 400 times higher) are observed at the watershed scales than the clast scale, despite changes in watershed characteristics such as watershed size, relief, and runoff values. The discrepancy is attributed to the fractal nature of the roughness and surface area across scales, i.e. the presence of undulations and fractures (e.g. roughness) at the bedrock-saprolite contact of the watershed that is generally not assessed in the watershed surface area estimates and most likely the main contributor to the constant rate difference of $\sim 1800$ times. 